Check for updates

Cite this: RSC Adv., 2021, 11, 15284

\section{Iron-catalysed hydroboration of non-activated imines and nitriles: kinetic and mechanistic studies $\uparrow$}

\begin{abstract}
Adineh Rezaei Bazkiaei, Michael Wiseman and Michael Findlater (D)*
Iron-catalysed hydroboration of imines and nitriles has been developed under low catalyst loading (1 mol\%) in the presence of HBpin. A wide scope of substrate was found to smoothly undergo hydroboration, including electron releasing/withdrawing and halogen substitution patterns and cyclic substrates which all afforded the corresponding amines in good to excellent yields. Dihydroboration of nitriles was achieved conveniently under solvent free and additive free conditions. Promisingly, this catalytic system is also capable of the hydroboration of challenging ketimine substrates. Preliminary kinetic analysis of imine hydroboration reveals a first-order dependence on catalyst concentration. Both HBpin and 4fluorophenyl- $N$-phenylmethanimine (1b) appear to exhibit saturation kinetics with first order dependence up to $0.5 \mathrm{mmol} \mathrm{HBpin}$ and $0.75 \mathrm{mmol}$ imine, respectively. Temperature-dependent rate experiments for imine hydroboration have also been explored. Activation parameters for the hydroboration of ${ }^{\mathrm{F}} \mathrm{PhC}=$ $\mathrm{NPh}(1 \mathrm{~b})$ were determined from the Eyring and Arrhenius plots with $\Delta S^{*}, \Delta H^{\neq}$, and $E_{\mathrm{a}}$ values of -28.69 $( \pm 0.3)$ e.u., $12.95( \pm 0.04) \mathrm{kcal} \mathrm{mol}^{-1}$, and $15.22( \pm 0.09) \mathrm{kcal} \mathrm{mol}^{-1}$, respectively.
\end{abstract}

Received 13th March 2021 Accepted 16th April 2021

DOI: 10.1039/d1ra02001c

rsc.li/rsc-advances catalysed hydroboration of allylamine in the presence of HBcat. ${ }^{33}$ Select examples of complexes capable of effecting catalytic imine hydroboration are shown in Fig. 1.

In 2009, Clark and co-workers reported a boron-substituted hydroxycyclopentadienyl ruthenium hydride catalyst with a limited substrate scope, three examples of aldimines, in hydroboration chemistry employing HBpin. ${ }^{34}$ Similarly, another ruthenium-based system capable of aldimine hydroboration was reported by Gunanathan in 2016 with a slightly broader altrogenous compounds using stoichiometric amounts of catalysed by precious metals in the presence of either pressurized $\mathrm{H}_{2}$ or via hydrogen transfer $^{\mathbf{1 0}}$ and hydrosilylation. ${ }^{\mathbf{1 1}}$ Hydroboration is an important transformation used to synthesize a wide variety of valuable products of industrial significance such as commodity and fine chemicals, agrochemicals and materials. ${ }^{12-15}$ Thus it is unsurprising that catalytic hydroboration of nitriles, ${ }^{\mathbf{1 6 - 2 0}}$ carbodiimides ${ }^{\mathbf{2 1 - 2 5}}$ and imines ${ }^{\mathbf{2 6 - 2 8}}$ are common methods used to prepare amines. Many experimental protocols have been studied $;^{29}$ catalysts employed in imine hydroboration range from main group elements, ${ }^{30-32}$ preciousmetals ${ }^{33-36}$ and, rare earth metals..$^{21,37}$

The first report of imine hydroboration catalysed by a transition metal was by Baker and Westcott and used a bidentate phosphine ligated gold(I) complex ( $5 \mathrm{~mol} \%$ ) and catecholborane in $1995 .{ }^{38}$ In 2001, the Westcott group reported a rhodium

Department of Chemistry \& Biochemistry, Texas Tech University, Lubbock, Texas 79409, USA.E-mail: michael.findlater@ttu.edu

$\dagger$ Electronic supplementary information (ESI) available: Full experimental details and NMR spectra. See DOI: 10.1039/d1ra02001c
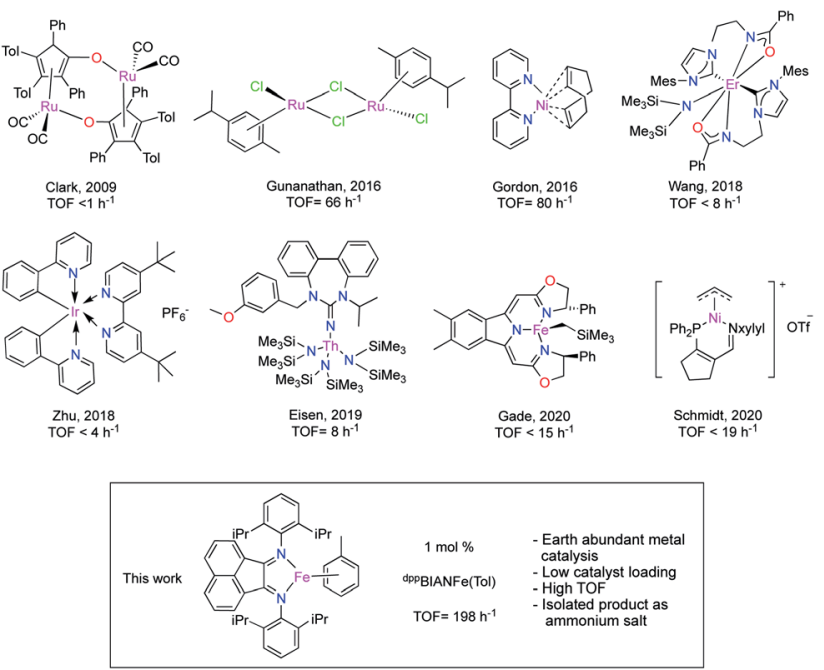

Fig. 1 Select (pre)catalysts reported in the literature for imine hydroboration and this report. 
substrate scope. $^{35} \mathrm{~A}$ fascinating dual-catalytic system was recently reported by the Zhu group. In this protocol, an inverse imine hydroboration (where boron adds to the carbon of the $\mathrm{C}=\mathrm{N}$ double bond) was achieved through cooperative organo-

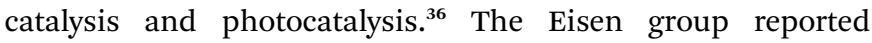
a thorium-catalysed hydroboration of aldimines with a broad substrate scope, however, this catalyst proved unsuccessful in ketimine reduction. ${ }^{37}$ While, there are several reports of catalytic imine hydroboration employing transition metals, first-row metal catalysis is still underdeveloped. In 2016, Gordon and coworkers demonstrated the catalytic hydroboration of imines with pinacolborane employing $\mathrm{Ni}$ (bpy)(cod) (bpy = 2,2-bipyridine, $\operatorname{cod}=1,5$-cyclooctadiene), as catalyst (in benzene) at room temperature with relatively low catalyst loadings. However, the substrate scope was very limited. ${ }^{39}$

Another base metal catalysed imine hydroboration was reported by the Zhang group in 2018, a Co(II) coordination polymer was employed as precatalyst, though this system was also effective with only a limited range of substrates. ${ }^{40}$ Very recently an iron catalyst was employed in enantioselective hydroboration of $N$-alkyl imines with a chiral bis(oxazolinylmethylidene)isoindoline pincer ligand by the Gade group. Asymmetric catalysis employing various acyclic $N$-alkyl imines afforded $\alpha$-chiral amines in excellent yields. ${ }^{41}$ The Schmidt group recently reported a cationic [(iminophosphine) nickel(allyl) $]^{+}$complex in the hydroboration of $\mathrm{N}$-allylimines ( $5 \mathrm{~mol} \%$ ). However, no successful hydroboration of ketimine is reported by this catalyst. ${ }^{42}$ Significantly, across all reports there have been limited examples of successful application of hydroboration strategies employing ketimine substrates; strongly indicating an ongoing need for more active/selective catalysts to be developed. The low abundance, high cost and toxicity of precious metal elements has prompted the catalytic community to focus heavily on an examination of the use of base metals in catalysis. ${ }^{43}$ Our group has a long standing interest in employing earth abundant metal catalysts in a variety of transformations such as aldehyde and ketone hydrosilylation, ${ }^{\mathbf{4}}$ imine hydrosilylation, ${ }^{\mathbf{1 1}}$ alkene and alkyne hydroboration, ${ }^{45}$ ester and amide reduction. ${ }^{\mathbf{4 6 , 4 7}}$ Iron has emerged as a leading candidate in 1st-row metal catalysis as it is the most abundant transition metal and the fourth most abundant element in the Earth's crust, it is environmentally benign, cost effective and has long-term commercial availability. ${ }^{48}$ Given the scarce number of literature reports in iron catalysed imine hydroboration, coupled with a lack of success with ketimine substrates specifically, we decided to study the application of iron systems in imine hydroboration.

\section{Results and discussion}

\section{Catalytic hydroboration of imines}

Initially, we examined the catalytic hydroboration of imines using $N$-benzylideneaniline (1a) as our model substrate. ${ }^{\mathrm{dpp}} \mathrm{BIANFe}(\mathrm{Tol})$ is readily prepared following the reported literature procedure. ${ }^{44}$ Hydroboration of 1a proceeded smoothly, as judged by ${ }^{1} \mathrm{H}$ NMR. As a control, the hydroboration reaction was repeated in the absence of ${ }^{\mathrm{dpp}} \mathrm{BIANFe}(\mathrm{Tol})$ and yield of $10 \%$ was observed (Table $\mathrm{S} 1 \dagger$ ). A range of different iron salts, from commercially available to synthesized complexes, was tested in catalysis and showed little to moderate activity (Table 1). In the interests of disclosure, use of $\mathrm{Fe}(\mathrm{OTf})_{3}$ revealed similar catalytic activity as ${ }^{\mathrm{dpp}} \mathrm{BIANFe}(\mathrm{Tol})$. However, our prior experience with ${ }^{\mathrm{dpp}} \mathrm{BIANFe}(\mathrm{Tol})$ and the synthetic modularity afforded by this ligand persuaded us to choose this precatalyst for further study. The use of an activator $\left(\mathrm{NaO}^{t} \mathrm{Bu}\right)$ in conjunction with ${ }^{\mathrm{dpp}} \mathrm{BIAN}$ $\mathrm{Fe}(\mathrm{Tol})$ resulted in a modest improvement in yield. A number of reaction variables were screened in an effort to optimize product yield: catalyst loading, temperature, solvent and, activator. Ultimately, employing toluene and $\mathrm{NaO}^{t} \mathrm{Bu}$ as the reaction solvent and activator, respectively, allowed us to maximize the yield of amine product (2a) to $97 \%$ (Tables S2-S4 $\dagger$ ). Finally, the reaction was found to be equally effective employing catecholborane (HBcat), the hydroboration product being isolated in $90 \%$ yield. However, a diminished yield (45\%) was obtained when a sterically encumbered borane ((9-borabicyclo[3.3.1] nonane)) was used. With optimized conditions in hand, we screened a variety of aldimine and ketimine substrates, which were easily accessed using well established literature procedures. ${ }^{10} \mathrm{~N}$-1-Diphenylethan-1-imine (1c) was cleanly converted to amine product $(2 \mathrm{c}, 84 \%)$ at low catalyst loading (1 mol\%) within $1 \mathrm{~h}$.

Encouraged by the successful conversion of a ketimine substrate employing ${ }^{\text {dpp } B I A N F e(T o l), ~ w e ~ d e c i d e d ~ t o ~ e x a m i n e ~}$ more ketimine substrates. Substitution patterns ranging from electron-releasing, withdrawing, heteroatom and sterically hindered groups were studied. Excellent product yields of more than $90 \%$ (within $\sim 2 \mathrm{~h}$ ) were obtained when employing substrates which feature electron withdrawing groups (2e, 2f, 2k). Similarly, a more electron-rich substrate (2d) also afforded product in very good yield (88\%). A thiophene-based ketimine substrate $(\mathbf{2 g})$ was also found to perform well under optimized

Table 1 Optimization of hydroboration conditions employing various iron salts ${ }^{a}$

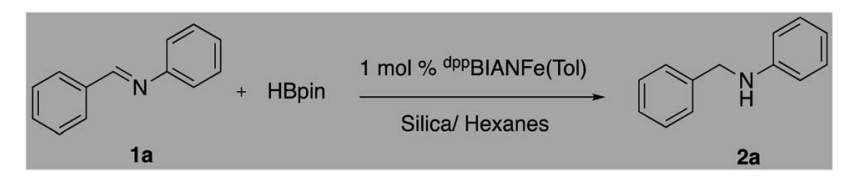

\begin{tabular}{lll}
\hline Entry & {$[\mathrm{Fe}]$} & Yield $^{b}(\%)$ \\
\hline 1 & ${ }^{\mathrm{dpp}} \mathrm{BIANFeCl}_{2}$ & 14 \\
2 & $\mathrm{Fe}(\mathrm{CO})_{5}$ & 54 \\
3 & ${ }_{\mathrm{dpp}} \mathrm{BIANFe}(\mathrm{Tol})$ & 87 \\
4 & $\mathrm{Fe}(\mathrm{acac})_{3}$ & 65 \\
5 & $\mathrm{FeCl}-\mathrm{Bpy}$ & $<10$ \\
6 & $\mathrm{Fe}(\mathrm{OTf})_{3}$ & 84 \\
$7^{c}$ & $\mathrm{dpP}_{\mathrm{BIANFe}(\mathrm{Tol})}$ & 97
\end{tabular}

${ }^{a}$ Reaction conditions: 1a ( $\left.0.5 \mathrm{mmol}\right)$, [Fe] (1 mol\%), HBpin (1.5 equiv.), THF, $70{ }^{\circ} \mathrm{C}, 20$ h. ${ }^{b}$ As determined by ${ }^{1} \mathrm{H}$ NMR employing mesitylene as internal standard. ${ }^{c}$ Optimized conditions: 1a $(0.5 \mathrm{mmol})$, ${ }^{d p p}$ BIANFe(Tol) (1 mol\%), HBpin (1.5 equiv.), $\mathrm{NaO}{ }^{t} \mathrm{Bu}$ (2 mol\%), toluene, $70{ }^{\circ} \mathrm{C}, 1 \mathrm{~h}$. 
reaction conditions, achieving good conversion (88\%) in only $1 \mathrm{~h}$. Finally, substrates which feature an enlarged steric profile $(\mathbf{2 h}, \mathbf{2 j})$ were also examined and revealed to be more recalcitrant substrates. Increased reaction times were required, and lower overall yields were observed. Moreover, to demonstrate the convenience of our approach, we have isolated reaction products as their ammonium salts following treatment with $1 \mathrm{M} \mathrm{HCl}$ in diethyl ether. Three examples are presented, $\mathbf{2 a}, \mathbf{2 b}$ and $\mathbf{2 g}$, affording isolated yields of 85, 65 and, 75\%, respectively (Scheme 1). Moreover, a gram scale reaction of 19 was carried out to demonstrate the synthetic applicability of this protocol. An isolated yield of $90 \%$ was obtained as ammonium salt (Scheme 1c).

\section{Catalytic hydroboration of nitriles}

We expanded our hydroboration studies to include nitriles, employing benzonitrile (3a) as a model substrate. ${ }^{16-20,37,49}$ Thus, exposure of $3 \mathbf{a}$ to ${ }^{\mathrm{dpp}} \mathrm{BIANFe}(\mathrm{Tol})(1 \mathrm{~mol} \%)$ and 2.5 equiv. HBpin afforded diborylated amine (4a) in $98 \%$ conversion within $3.5 \mathrm{~h}$.
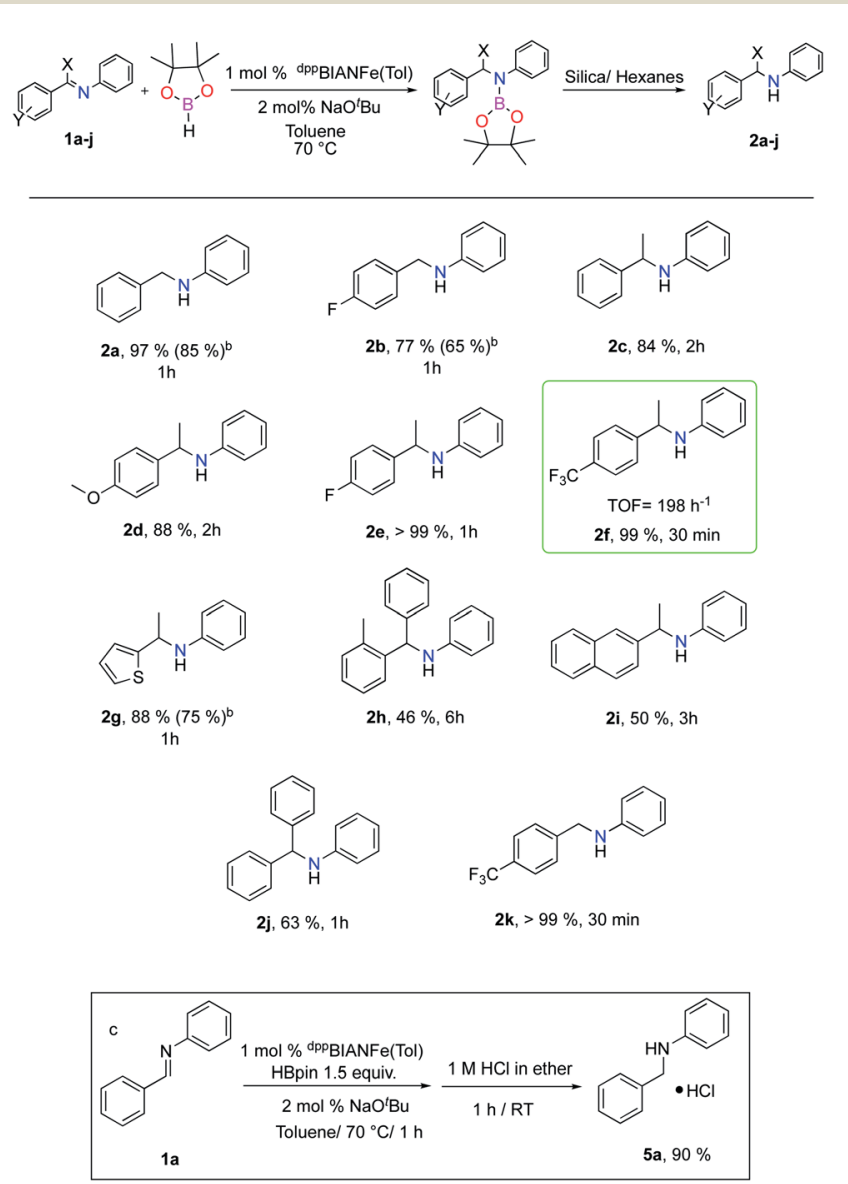

Scheme 1 Hydroboration of imines and their subsequent conversion to secondary amines. Reaction conditions: imine $(0.5 \mathrm{mmol})$, HBpin

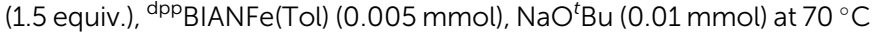
in toluene; conversions were determined by ${ }^{1} \mathrm{H}$ NMR employing mesitylene as internal standard. 'Isolated yield as ammonium salt in parentheses. "Scale-up reaction of catalytic hydroboration of $\mathrm{N}$ benzylideneaniline; isolated yield as ammonium salt.
The reaction was carried out under solvent- and additive-free conditions under mild (RT) conditions. A small scope of substrate was explored, and the reaction was found to tolerate both electron-releasing and withdrawing substituents. Bromoand chloro-substitution were tolerated and aliphatic (cyclic) substrates all afforded diborylated amines in good to excellent yields. Substrates with electron-withdrawing functional groups $(-\mathrm{F},-\mathrm{Cl},-\mathrm{Br})$ on the backbone were well tolerated and yields ranging from good to excellent (81-95\%) were obtained within 2 to $3 \mathrm{~h}$ at $70{ }^{\circ} \mathrm{C}(\mathbf{4 b}-\mathbf{4 d})$. A nitrile substrate with an electron releasing group (-OMe) afforded product in $99 \%$ yield within $6 \mathrm{~h}$ at $70{ }^{\circ} \mathrm{C}(\mathbf{4 e})$. Cyclohexanecarbonitrile also afforded the corresponding diborylated product (4f) in $83 \%$ yield in $6 \mathrm{~h}$ (Scheme 2). Following a similar procedure as employed in the isolation of imine hydroboration products, the treatment of nitrile hydroboration products with $1 \mathrm{M} \mathrm{HCl}$ (ether) facilitated easy isolation of the corresponding ammonium salts. Two substrates were chosen to demonstrate the utility of this approach, 4b and 4d were isolated in 84 and $77 \%$ yields, respectively.

\section{Preliminary mechanistic study of imine hydroboration}

To gain insight into the mechanism of imine hydroboration including possible modes of activation of the precatalyst ${ }^{\mathrm{dpp}}$ BIANFe(Tol), we conducted a series of experiments. Thus, stoichiometric reactions to generate plausible reaction intermediates, preliminary study of reactions kinetics including temperature-dependent reaction rate experiments were performed. Reactions between ${ }^{\mathrm{dpp}} \mathrm{BIANFe}(\mathrm{Tol})$ and model imine 1a

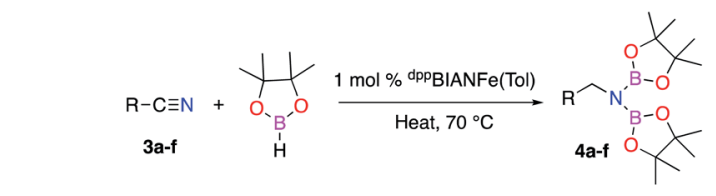

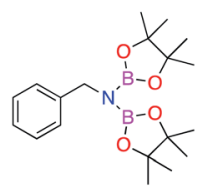

$4 a^{b}, 98 \%, 3.5 h$

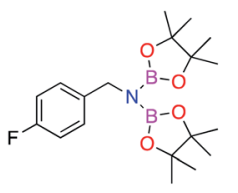

4b, $95 \%(84 \%)^{c}$

$3 \mathrm{~h}$

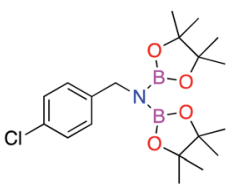

4c, $81 \%, 2 \mathrm{~h}$

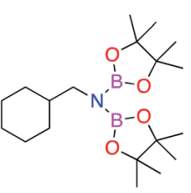

4f, $83 \%, 6 \mathrm{~h}$

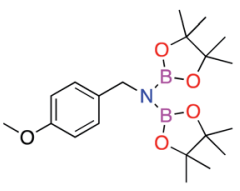

$4 e, 99 \%, 6 \mathrm{~h}$<smiles>CC1(C)OB(N(Cc2ccc(Br)cc2)B2OC(C)(C)C(C)(C)O2)OC1(C)C</smiles>

$$
\begin{aligned}
& \text { 4d, } 84 \%(77 \%)^{c} \\
& 3 \mathrm{~h}
\end{aligned}
$$

Scheme 2 Catalytic hydroboration of nitriles to diboryl amines. ${ }^{a}$ Reaction conditions: nitriles $(0.25 \mathrm{mmol}), \mathrm{HBpin}(2.5$ equiv.), ${ }^{\mathrm{dpp}}$ BIANFe(Tol) $(0.0025 \mathrm{mmol})$ at $70{ }^{\circ} \mathrm{C}$; yields were determined by ${ }^{1} \mathrm{H}$ NMR employing mesitylene as internal standard. ${ }^{\mathrm{b}}$ Reaction was carried out at room temperature. "Isolated yield as ammonium salt in parentheses. 


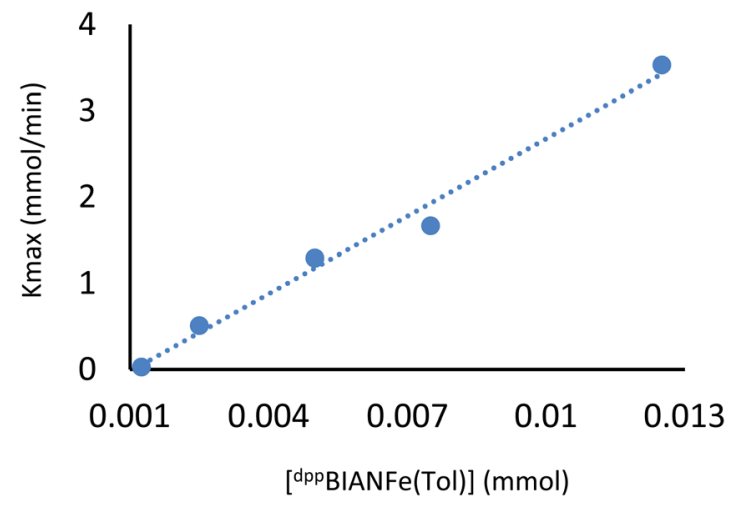

Fig. 2 Plot of initial reaction rates $(\delta p / \delta t) v s .{ }^{d p p} B I A N F e(T o l)$.

( 1 and 3 equiv. of the imine), were carried out at both room temperature and $70{ }^{\circ} \mathrm{C}$; we concluded that ${ }^{\mathrm{dpp}}$ BIANFe(Tol) by itself, does not appear to react directly with imine substrate even after prolonged exposure at elevated temperature (Fig. S8 $\dagger$ ). Moreover, stoichiometric reaction of ${ }^{\mathrm{dpp}} \mathrm{BIANFe}(\mathrm{Tol})$ with HBpin at either room temperature or $70{ }^{\circ} \mathrm{C}$ did not afford any detectable new product(s), as evidenced by in situ monitoring employing ${ }^{11} \mathrm{~B}$ NMR spectroscopy. However, upon addition of stoichiometric amounts of $\mathrm{NaO}^{t} \mathrm{Bu}$ to the same reaction mixture we observed complete consumption of HBpin. The signal attributed to HBpin at $\delta 27 \mathrm{ppm}$ in the ${ }^{11} \mathrm{~B}$ NMR spectrum disappeared, followed by the formation of a new signal at $\delta 20 \mathrm{ppm}$ (Fig. S9†). This result can be interpreted as the requirement of precatalyst activation employing $\mathrm{NaO}^{t} \mathrm{Bu}$ to form an active catalyst either via direct interaction with HBpin, ${ }^{50}$ then subsequent reaction with ${ }^{\mathrm{dpp}}{ }_{\text {BIANFe(Tol) or }}$ a synergistic effect of all three species. Alas, our attempts to isolate organometallic species from stoichiometric reactions were unsuccessful. Preliminary kinetic analysis of the catalytic hydroboration reaction was performed by observing the disappearance of 4 -fluorophenyl- $N$-phenylmethanimine (1b) which is conveniently monitored using ${ }^{19} \mathrm{~F}$ NMR spectroscopy (Fig. S1 $\dagger$ ). A plot of the initial rate of the disappearance of $\mathbf{1 b}$ exhibits a first-order dependence on the catalyst (Fig. 2). While varying

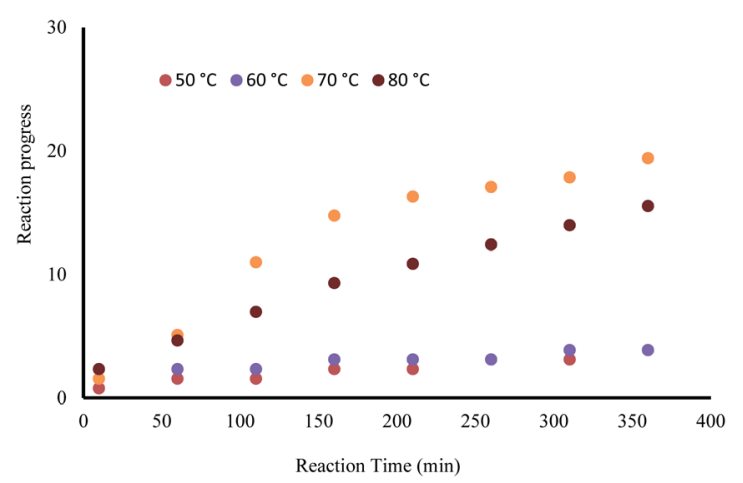

Fig. 3 Reaction profile of catalytic hydroboration of 4-fluorophenyl$\mathrm{N}$-phenylmethanimine with $\mathrm{HBpin}$ using ${ }^{\mathrm{dpp} B I A N F e(T o l)}$ as catalyst at different temperatures.

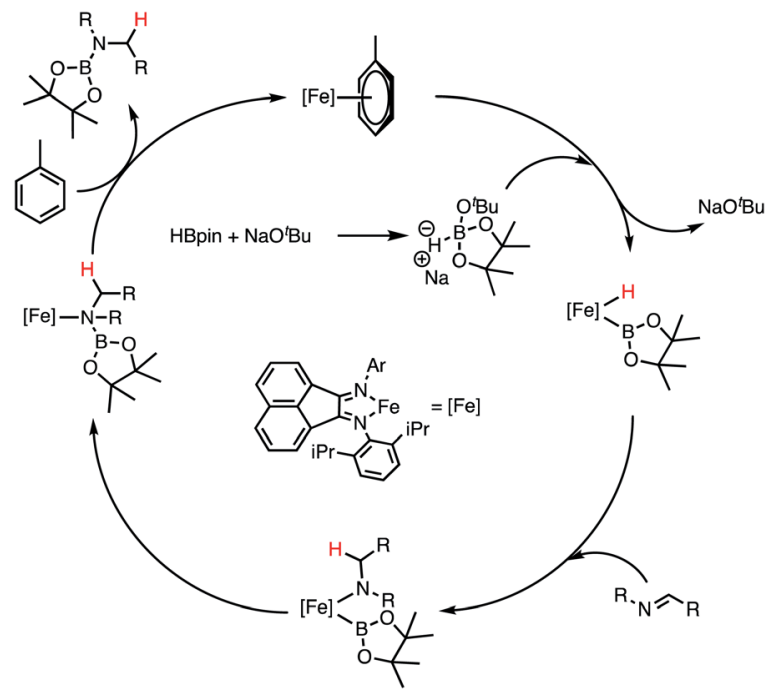

Scheme 3 Plausible mechanism for imine hydroboration.

the concentration of either HBpin or $\mathbf{1 b}$ appeared to reveal saturation kinetics, whereby the reaction is first order in both HBpin and imine (1) only up to 0.5 and $0.75 \mathrm{mmol}$ respectively (Fig. $\mathrm{S} 2$ and $\mathrm{S} 4 \dagger$ ).

The reaction profile of catalytic hydroboration of 4-fluorophenyl- $N$-phenylmethanimine at different temperatures is depicted in Fig. 3. Activation parameters for the hydroboration of ${ }^{\mathrm{F}} \mathrm{PhC}=\mathrm{NPh}$ were determined from the Eyring and Arrhenius plots with $\Delta S^{\neq}, \Delta H^{\neq}$, and $E_{\mathrm{a}}$ values of $-28.69( \pm 0.3)$ e.u., 12.95 $( \pm 0.04) \mathrm{kcal} \mathrm{mol}^{-1}$, and $15.22( \pm 0.09) \mathrm{kcal} \mathrm{mol}^{-1}$, respectively (Fig. S6 and S7†). The negative activation entropy indicates that the rate-determining step involves an associative process and $\Delta H^{\neq}$and $\Delta S^{\neq}$data are consistent with concerted bond-cleavage and bond-formation process with an organized four-centered transition state, respectively. Data obtained at $70{ }^{\circ} \mathrm{C}$ appears to show anomalously high reaction rates. Multiple kinetics runs at this same temperature showed the same data; we are still investigating the cause.

On the basis of both our preliminary studies and previous reported literature, a plausible hydroboration mechanism is proposed for the reaction of ${ }^{\mathrm{dpp}} \mathrm{BIANFe}(\mathrm{Tol})$ and $\mathrm{PhC}=\mathrm{NPh}$ (1a) in the presence of HBpin (Scheme 3). The first step in the catalytic cycle is loss of toluene from ${ }^{\mathrm{dpp}} \mathrm{BIANFe}(\mathrm{Tol})$ concomitant with generation of a new HBpin complex. Exposure of this species to imine substrate produces an iron(boryl)(amine) after insertion of the $\mathrm{C}=\mathrm{N}$ bond into an iron-hydride. Reductive elimination of the aminoborane product followed by rebinding of the toluene-cap would close the catalytic cycle.

\section{Conclusions}

In conclusion, the rapid hydroboration of imines to the corresponding secondary amines have been developed using ${ }^{\mathrm{dPp}}$ BIANFe(Tol) as precatalyst in the presence of HBpin. Hydroboration products can be conveniently isolated as the corresponding ammonium salts via treatment with $\mathrm{HCl}$ as a $1 \mathrm{M}$ 
solution in diethyl ether. To the best of our knowledge, this catalyst has the highest TOF $\left(198 \mathrm{~h}^{-1}\right)$ amongst previously reported transition and rare earth metal complexes to carry out the efficient hydroboration of imines. Moreover, this catalytic system proved capable of the reduction of ketimine substrates in good to excellent yields, which are considered more challenging substrates to reduce. In addition, ${ }^{\mathrm{dpp}} \mathrm{BIANFe}(\mathrm{Tol})$ was found to be an effective precatalyst in the hydroboration of nitriles under solvent free and additive free condition to form diboryl amines with excellent yields.

\section{Author contributions}

ARB and MF designed and executed the project. ARB and MW carried out the experimental work. ARB and MF wrote the manuscript.

\section{Conflicts of interest}

There are no conflicts to declare.

\section{Acknowledgements}

The authors gratefully acknowledge the National Science Foundation (CHE-1554906) for financial support of this work.

\section{Notes and references}

1 J. Verduyckt, R. Coeck and D. E. De Vos, ACS Sustainable Chem. Eng., 2017, 5, 3290-3295.

2 M. A. Blaskovich, J. Med. Chem., 2016, 59, 10807-10836.

3 R. Jastrząb, L. Łomozik and B. Tylkowski, Phys. Sci. Rev., 2016, 1, 69-106.

4 R. Mesnage, C. Benbrook and M. N. Antoniou, Food Chem. Toxicol., 2019, 128, 137-145.

5 B. Movassagh, H. Rooh and H. Bijanzadeh, Chem. Heterocycl. Compd., 2013, 48, 1719-1721.

6 J. T. Colyer, N. G. Andersen, J. S. Tedrow, T. S. Soukup and M. M. Faul, J. Org. Chem., 2006, 71, 6859-6862.

7 A. D. Dorsey, J. E. Barbarow and D. Trauner, Org. Lett., 2003, 5, 3237-3239.

8 S. F. Zhu, J. B. Xie, Y. Z. Zhang, S. Li and Q. L. Zhou, J. Am. Chem. Soc., 2006, 128, 12886-12891.

9 Y. Liu and H. Du, J. Am. Chem. Soc., 2013, 135, 6810-6813.

10 J. S. Samec and J. E. Bäckvall, Chem.-Eur. J., 2002, 8, 29552961.

11 A. Saini, C. R. Smith, F. S. Wekesa, A. K. Helms and M. Findlater, Org. Biomol. Chem., 2018, 16, 9368-9372.

12 C. C. Chong, B. Rao and R. Kinjo, ACS Catal., 2017, 7, 58145819.

13 J. Magano and J. R. Dunetz, Org. Process Res. Dev., 2012, 16, 1156-1184.

14 S. R. Tamang, A. Singh, D. K. Unruh and M. Findlater, ACS Catal., 2018, 8, 6186-6191.

15 M. Haberberger and S. Enthaler, Chem.-Asian J., 2013, 8, 5054.
16 T. Kitano, T. Komuro and H. Tobita, Organometallics, 2019, 38, 1417-1420.

17 H. Ben-Daat, C. L. Rock, M. Flores, T. L. Groy, A. C. Bowman and R. J. Trovitch, Chem. Commun., 2017, 53, 7333-7336.

18 J. B. Geri and N. K. Szymczak, J. Am. Chem. Soc., 2015, 137, 12808-12814.

19 M. Ito, M. Itazaki and H. Nakazawa, Inorg. Chem., 2017, 56, 13709-13714.

20 A. D. Ibrahim, S. W. Entsminger and A. R. Fout, ACS Catal., 2017, 7, 3730-3734.

21 Y. Yuan, X. Wang, Y. Li, L. Fan, X. Xu, Y. Chen, G. Li and W. Xia, Organometallics, 2011, 30, 4330-4341.

22 A. Ramos, A. Antiñolo, F. Carrillo-Hermosilla, R. FernándezGalán and D. García-Vivó, Chem. Commun., 2019, 55, 30733076.

23 Y. Ding, X. Ma, Y. Liu, W. Liu, Z. Yang and H. W. Roesky, Organometallics, 2019, 38, 3092-3097.

24 M. Rauch, S. Ruccolo and G. Parkin, J. Am. Chem. Soc., 2017, 139, 13264-13267.

25 Q. Shen, X. Ma, W. Li, W. Liu, Y. Ding, Z. Yang and H. W. Roesky, Chem.-Eur. J., 2019, 25, 11918-11923.

26 Q. Yin, Y. Soltani, R. L. Melen and M. Oestreich, Organometallics, 2017, 36, 2381-2384.

27 M. Arrowsmith, M. S. Hill and G. Kociok-Köhn, Chem.-Eur. J., 2013, 19, 2776-2783.

28 D. Bedi, A. Brar and M. Findlater, Green Chem., 2020, 22, 1125-1128.

29 D. Hayrapetyan and A. Y. Khalimon, Chem.-Asian J., 2020, 15, 2575-2587.

30 M. R. Adams, C. H. Tien, B. S. Huchenski, M. J. Ferguson and A. W. Speed, Angew. Chem., 2017, 56, 6268-6271.

31 M. K. Bisai, S. Pahar, T. Das, K. Vanka and S. S. Sen, Dalton Trans., 2017, 46, 2420-2424.

32 C. H. Tien, M. R. Adams, M. J. Ferguson, E. R. Johnson and A. W. Speed, Org. Lett., 2017, 19, 5565-5568.

33 C. M. Vogels, P. E. O'Connor, T. E. Phillips, K. J. Watson, M. P. Shaver, P. G. Hayes and S. A. Westcott, Can. J. Chem., 2001, 79, 1898-1905.

34 L. Koren-Selfridge, H. N. Londino, J. K. Vellucci, B. J. Simmons, C. P. Casey and T. B. Clark, Organometallics, 2009, 28, 2085-2090.

35 A. Kaithal, B. Chatterjee and C. Gunanathan, J. Org. Chem., 2016, 81, 11153-11161.

36 N. Zhou, X. A. Yuan, Y. Zhao, J. Xie and C. Zhu, Angew. Chem., 2018, 130, 4054-4058.

37 S. Saha and M. S. Eisen, ACS Catal., 2019, 9, 5947-5956.

38 R. T. Baker, J. C. Calabrese and S. A. Westcott, J. Organomet. Chem., 1995, 498, 109-117.

39 A. E. King, S. C. E. Stieber, N. J. Henson, S. A. Kozimor, B. L. Scott, N. C. Smythe, A. D. Sutton and J. C. Gordon, Eur. J. Inorg. Chem., 2016, 1635-1640.

40 J. Wu, H. Zeng, J. Cheng, S. Zheng, J. A. Golen, D. R. Manke and G. Zhang, J. Org. Chem., 2018, 83, 9442-9448.

41 C. K. Blasius, N. F. Heinrich, V. Vasilenko and L. H. Gade, Angew. Chem., 2020, 132, 16108-16111.

42 I. Hossain and J. A. R. Schmidt, Eur. J. Inorg. Chem., 2020, 1877-1884. 
43 S. R. Tamang and M. Findlater, Molecules, 2019, 24, 3194.

44 F. S. Wekesa, R. Arias-Ugarte, L. Kong, Z. Sumner, G. P. McGovern and M. Findlater, Organometallics, 2015, 34, 5051-5056.

45 A. Singh, S. Shafiei-Haghighi, C. R. Smith, D. K. Unruh and M. Findlater, Asian J. Org. Chem., 2020, 9, 416-420.

46 S. R. Tamang, A. F. Cozzolino and M. Findlater, Org. Biomol. Chem., 2019, 17, 1834-1838.
47 S. R. Tamang, A. Singh, D. Bedi, A. R. Bazkiaei, A. A. Warner, K. Glogau, C. McDonald, D. K. Unruh and M. Findlater, Nat. Catal., 2020, 3, 154-162.

48 M. D. Greenhalgh, A. S. Jones and S. P. Thomas, ChemCatChem, 2015, 7, 190-222.

49 Z. Huang, S. Wang, X. Zhu, Q. Yuan, Y. Wei, S. Zhou and X. Mu, Inorg. Chem., 2018, 57, 15069-15078.

50 J. H. Docherty, J. Peng, A. P. Dominey and S. P. Thomas, Nat. Chem., 2017, 9, 595. 